\title{
A Mathematical Modelling Approach in the Spread of the Novel 2019 Coronavirus SARS-CoV-2 (COVID-19) Pandemic
}

\author{
Zafer Cakir ${ }^{1 \star}$, Hasan Basri Savas ${ }^{2}$
}

\begin{abstract}
${ }^{1}$ Alanya Alaaddin Keykubat University, Faculty of Education, Department of Mathematics Teaching, Antalya, TURKEY ${ }^{2}$ Alanya Alaaddin Keykubat University, Faculty of Medicine, Department of Medical Biochemistry, Antalya, TURKEY

*Corresponding Author: zafer.cakir@alanya.edu.tr
\end{abstract}

Citation: Cakir Z, Savas HB. A Mathematical Modelling Approach in the Spread of the Novel 2019 Coronavirus SARS-CoV-2 (COVID-19) Pandemic. Electron J Gen Med. 2020;17(4):em205. https://doi.org/10.29333/ejgm/7861

ARTICLE INFO

Received: 24 Mar. 2020

Accepted: 27 Mar. 2020

\begin{abstract}
The novel 2019 coronavirus, SARS-CoV-2 (COVID-19), emerged towards the end of 2019 in the city of Wuhan in the province of Hubei in the People's Republic of China, and it has spread to the entire world very fast and in a very short time. This study aimed to investigate the course of the pandemic by mathematical modelling based on the information that the time-dependent change (spreading) rate of the $\mathrm{H}$ number of individuals who have caught a contagious disease is proportional to the multiplication of the numbers of those who have caught the disease and those who have not. According to the results of the mathematical modelling in our study, in the case that sufficient precautions are not taken, or precautions are reduced, the course of the pandemic may show a very fast change in the negative direction. For this reason, every precaution, individual or social, will be significant in terms of the course of the COVID-19 pandemic.
\end{abstract}

Keywords: COVID-19, laboratory, pandemic progression, mathematical modelling

\section{INTRODUCTION}

The novel 2019 coronavirus, SARS-CoV-2 (COVID-19), emerged towards the end of 2019 in the city of Wuhan in the province of Hubei in the People's Republic of China, and it has spread to the entire world very fast and in a very short time. With the respiratory tract infection that it causes, the virus leads to pneumonia characterized by an appearance like frosted glass. The infection, which has progressed in a highly destructive manner especially in China, Iran and Italy and caused large numbers of deaths, is continuing to spread (1-3). The first diagnosis of COVID-19 in Turkey was made on 10 March 2020. Until 26 March 2020, the number of COVID-19-positive cases reached 3629 , while the number of related deaths increased to 75 (4). The diagnosis of COVID-19 is made by reverse transcription - polymerase chain reaction (RT-PCR) tests. With the help of Chinese scientists sharing genomic information on the virus fast with the entire world, it has become possible to conduct RT-PCR analyses without the virus completely spreading in the world. COVID-19 RT-PCR analysis has provided a significant opportunity in fighting with the pandemic that has emerged. However, some patients may have negative RT-PCR analysis results but positive clinical findings. In these cases, the RT-PCR analysis results may turn out positive in following days. Therefore, in the diagnosis of the disease, clinical findings are as important as laboratory findings. Additionally, in routine biochemical analyses, increases in the serum C-reactive protein (CRP), lactate dehydrogenase (LDH), erythrocyte sedimentation rate (ESR), monocyte volume distribution width (MDW) and D-dimer levels and a decrease in albumin concentration may be expected (5). Due to the gravity of the COVID-19 pandemic, the necessity of scientific modelling is clear in terms of being able to make medical planning and see the long-term course of the pandemic. This study aimed to investigate the course of the pandemic by mathematical modelling based on the information that the time-dependent change (spreading) rate of the $\mathrm{H}$; number of individuals who have caught a contagious disease is proportional to the multiplication of the numbers of those who have caught the disease and those who have not.

\section{MATERIALS AND METHODS}

In the literature, for a region with a population $P$ (city, country), it is stated that "the time-dependent change (spreading) rate of the $\mathrm{H}$; number of individuals who have caught a contagious disease is proportional to the multiplication of the numbers of those who have caught the disease and those who have not" (6). The mathematical model of this situation is given by the following differential equation,

$$
\frac{d H}{d t}=\mu H(P-H)
$$

Here, $\mu$ is the proportionality constant.

In this study, the model above was revised specifically for the "corona pandemic" and discussed in the form of "the spreading rate of the disease $\left(\frac{d H}{d t}\right)$; is directly proportional with the multiplication of the numbers of those who have 
caught the disease and those who have not, and inversely proportional with the square root of time-variable". The variables and parameters that were considered while forming the mathematical model of the issue were as follows:

$t$ : Independent time variable in units of days,

$H(t)$ : Dependent variable expressing the number of patients at the time $t$,

$\frac{\boldsymbol{d} \boldsymbol{H}}{\boldsymbol{d} \boldsymbol{t}}$ : Derivative corresponding to the time-dependent change (spreading) rate of the disease,

$\mu$ : A parameter that covers all factors that influence the spreading rate.

Furthermore, let the initial $(t=0)$ number of patients be $H(0)=H_{0}$, the number of patients at a time $t=t_{1}$ given as additional information be $H\left(t_{1}\right)=H_{1}$ and the number of individuals who are open to the disease be $P$.

The purpose of the study is, in the model given in (Eq.1), to take the right-hand side as a function of the time variable $t$, and with the help of a modified mathematical model to be more compatible with actual data, to obtain more reliable data regarding the course of the disease in the progression of time. For this, by using the expression $\mu=\mu(t)=\frac{k}{2 \sqrt{t}}$ dependent on the $t$-time variable instead of the constant $\mu$ on the right-hand side, we are proposing the following initial value problem (IVP) related to the issue as,

$$
\left\{\begin{array}{c}
\frac{d H}{d t}=\mu H(P-H) \\
H(0)=H_{0} \\
H\left(t_{1}\right)=H_{1}
\end{array}\right.
$$

Here, $k$ is a positive proportional constant.

The solution of this problem (Eq.1)-(Eq.3) will provide a formula related to how many people could get sick after how many days, that is, a time-dependent analytical function in units of days.

Firstly, solving the (Eq.2) differential equation in the separable variables type, we have

$$
\begin{gathered}
\frac{d H}{d t}=\frac{k}{2 \sqrt{t}} H(P-H) \\
\Rightarrow \int \frac{d H}{H(P-H)}=\int \frac{k}{2 \sqrt{t}} d t \\
\Rightarrow \ln H-\ln (P-H)=P k \sqrt{t}+\ln c \\
\Rightarrow \frac{H}{(P-H)}=c e^{P k \sqrt{t}} \\
\Rightarrow H(t)=\frac{P c}{\left(e^{-P k \sqrt{t}}+c\right)}
\end{gathered}
$$

using initial condition, we get

$$
\begin{gathered}
H(0)=H_{0}=\frac{P c}{\left(e^{0}+c\right)} \\
\Rightarrow c=\frac{H_{0}}{P-H_{0}} .
\end{gathered}
$$

Then, to determine $k$-parameter, let's use additional data

$$
\begin{gathered}
H\left(t_{1}\right)=H_{1} \\
H\left(t_{1}\right)=H_{1}=\frac{P c}{c+e^{P k \sqrt{t_{1}}}} \\
\Rightarrow P k=\frac{1}{\sqrt{t_{1}}} \ln \left(\frac{H_{0}\left(P-H_{1}\right)}{H_{1}\left(P-H_{0}\right)}\right)
\end{gathered}
$$

Finally writing (Eq.6) and (Eq.7) into (Eq.5), solution of given IVP (Eq.2)-(Eq.4) is obtained as,

$$
H(t)=\frac{P}{\left(1+\frac{1}{c} e^{-d \sqrt{t}}\right)} .
$$

Here, $d=\ln \left(\frac{H_{0}\left(P-H_{1}\right)}{H_{1}\left(P-H_{0}\right)}\right) / \sqrt{t_{1}}$.

\section{RESULTS}

Now, in the case that the potential number of individuals open to getting the disease is $\mathrm{P}=100000$, using the date 15 March 2020 as $t=0, H(0)=H_{0}=18$ patients; $t_{1}=11$ as 26 March 2020 with $H\left(t_{1}\right)=H(11)=H_{1}=3629$ patients, let us assess the figure below where we may observe the behavior of the spread (approximate number of cases) in a 30-day future time interval ahead of us.

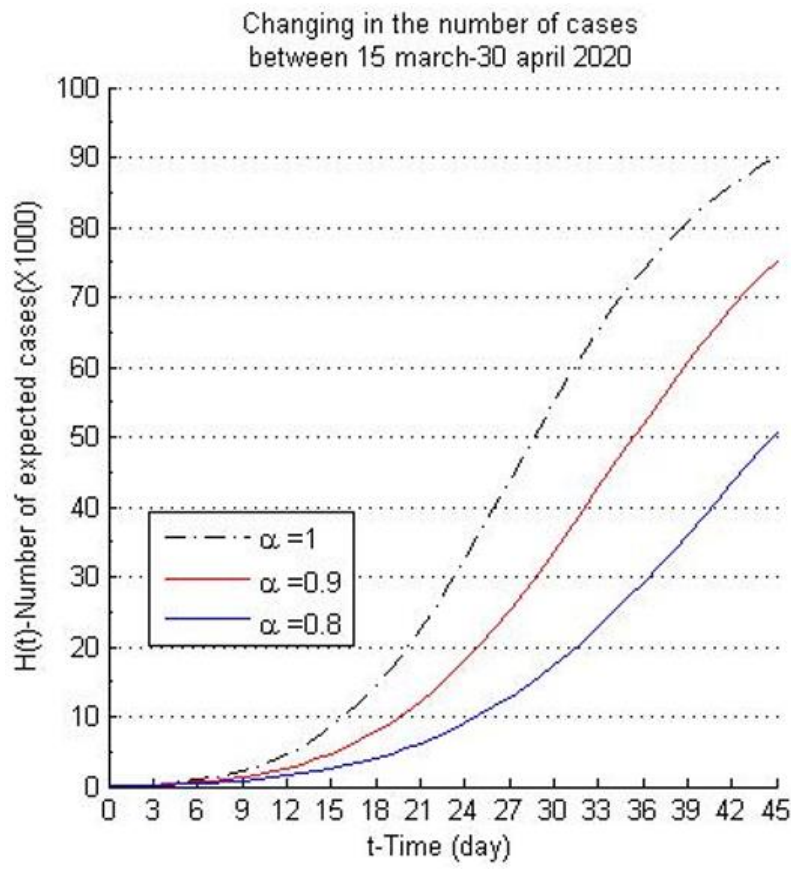

Figure 1. Different trends of number of cases based on an $\alpha$

Figure 1 reflects the different trends based on an $\alpha$-control parameter that also contains the exponential reflection of the precautions that are taken, from the solution we obtained by utilizing the mathematical model we established. Accordingly:

$\alpha=1 \quad$ : Corresponds to the continuation of the existing situation.

$\alpha=0.9$ : Corresponds to the situation of a $10 \%$ increase in precautions.

$\alpha=0.8$ : Corresponds to the situation of a $20 \%$ increase in precautions. 


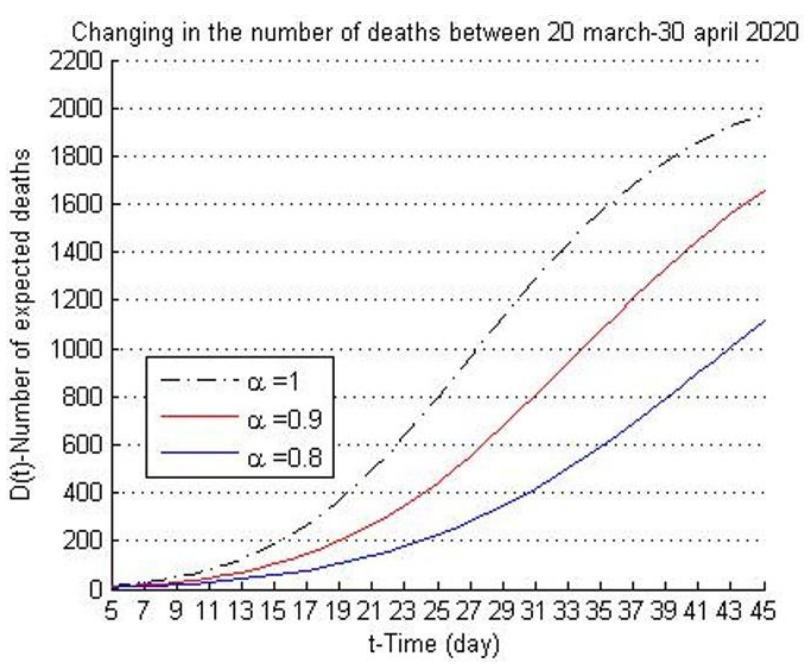

Figure 2. Different trends of number of deaths based on an $\alpha$

\section{DISCUSSION}

COVID-19 is an enveloped RNA virus. It induces a respiratory tract infection. It shows a very fast spreading behavior. Its mortality rate around the world is around $3 \%$. Clinical laboratory analyses and imaging methods are used for the diagnosis of a COVID-19 infection. It is aimed to make the diagnosis at the laboratory by RT-PCR and routine biochemical analyses and direct lung radiography and computerized tomography in radiological imaging. It does not have an effective vaccine or an exact and effective treatment scheme. It shows a destructive effect especially in individuals with weak immune systems. Intensive care and mechanical ventilation may be required in the treatment process $(1-5,7)$. Various precautions are applied to prevent it from spreading. The data that were created as a result of our study showed that increasing the precautions will reduce the very fast spread of the pandemic situation. These numbers show us the significance of abiding by the precautions that are taken (how much they affect the outcomes). As the amount of increase in the spread of the disease has an "exponential" change as known, precautions have an effective role in reducing the spreading rate of the disease. The different spreading rates of the disease in every country may be explained by the different precautions that are taken. According to the results of the analysis we carried out on the mathematical modelling in our study, even a small increase in precautions will create a large difference in terms of the numbers of patients.

\section{CONCLUSION}

According to the results of the mathematical modelling in our study, in the case that sufficient precautions are not taken, or precautions are reduced, the course of the pandemic may show a very fast change in the negative direction. For this reason, every precaution, individual or social, will be significant in terms of the course of the COVID-19 pandemic. It will be highly useful to take care of especially personal hygiene individually, apply social isolation, strengthen the immune system by natural and healthy nutrition, socially support social isolation, scan those with symptoms of COVID-19 infection by laboratory tests and take care especially for those who are at older ages.

\section{REFERENCES}

1. Lau H, Khosrawipour V, Kocbach P, Mikolajczyk A, Ichii H, Schubert J, Bania J, Khosrawipour T. Internationally lost COVID-19 cases. J Microbiol Immunol Infect. 2020;14. pii: S1684-1182(20)30073-6. https://doi.org/10.1016/j.jmii. 2020.03.013 PMid:32205091

2. Hu TY, Frieman M, Wolfram J. Insights from nanomedicine into chloroquine efficacy against COVID-19. Nat Nanotechnol. 2020;23. https://doi.org/10.1038/s41565020-0674-9 PMCid:PMC7094976

3. Zhang L, Lin D, Sun X, Curth U, Drosten C, Sauerhering L, Becker S, Rox K, Hilgenfeld R. Crystal structure of SARSCoV-2 main protease provides a basis for design of improved a-ketoamide inhibitors. Science. 2020;20. pii: eabb3405. https://doi.org/10.1126/science.abb3405 PMid: 32198291

4. AA. Coronavirus Infection Map. Available at: https://www.aa.com.tr/en/p/coronavirus-infection-map (Accessed: 26 March 2020).

5. Lippi G, Plebani M. The critical role of laboratory medicine during coronavirus disease 2019 (COVID-19) and other viral outbreaks. Clin Chem Lab Med. 2020;19. pii: /j/cclm.aheadof-print/cclm-2020-0240/cclm-2020-0240.xml. https://doi.org/10.1515/cclm-2020-0240 PMid:32191623

6. Edwards $\mathrm{CH}$, Penney DE. Differential Equations and Boundary Value Problems: Computing and Modeling. Pearson Prentice Hall, 2008.

7. Abdulamir AS, Hafidh RR. The Possible Immunological Pathways for the Variable Immunopathogenesis of COVID19 Infections among Healthy Adults, Elderly and Children. Electron J Gen Med. 2020;17(4):em202. https://doi.org/ 10.29333/ejgm/7850 